\section{Reed-Elsevier's hypocrisy in selling arms and health}

\section{Authors should take the lead in making the company divest its arms business}

Can you imagine a tobacco company publishing health journals? Probably not. The journals would be suspect. The hypocrisy would be too brazen for all but the most cynical of investors. And surely the company's business mission would be impossibly confused: would the company be in the business of killing people or keeping them alive? But if you can't imagine that absurdity, can you imagine a company that simultaneously promotes arms sales and publishes health journals? Well, you don't have to imagine such a company-because it exists. Indeed, it is Reed Elsevier, the world's largest publisher of scientific and medical journals. And the finest of Reed Elsevier's journals is The Lancet, the leading global health journal, which has been receiving much attention from the Pentagon for its important articles showing that death rates in Iraq are far above those admitted by the United States government. ${ }^{1,2}$ This is the absurd world of Ionesco. How did it happen, and how should the company and the editors, authors and readers of its journals respond?

There are nearly 650 million guns and light weapons in the world, and each year some eight million more are added. ${ }^{3}$ Every year about half a million people are killed by armed violence. Most of those who die are civilians, particularly women and children. Since the Second World War, $85 \%$ of armed conflicts have been in the poor world. ${ }^{4}$ By 2020, deaths and injuries from war and violence will overtake deaths from infectious disease. ${ }^{5}$ It was The Lancet that published the study which told us that war and armed conflicts are the main barriers to development in poor countries, and expenditure on arms diverts resources from education and health. Yet last year's United Nation's conference on small arms collapsed without agreement, as MacDonald's article in The Lancet told us. ${ }^{3}$

Through its subsidiary, Reed Exhibitions, Reed Elsevier runs arms fairs in Britain, the United States, the Middle East, Brazil, Germany and Taiwan. The same subsidiary runs Lancet conferences, including the forthcoming one in Asia. The Lancet told us how the fairs have in the past included cluster bombs, which are especially dangerous to civilians because they fail to explode and thus create minefields. ${ }^{6}$ The Lancet has consistently spoken out against cluster bombs. Last year's fair in the US included torture equipment sold by Security Equipment Corporation, who use the grotesque slogan 'Making grown men cry since 1975.' The Lancet has long been a leader in condemning torture.
You will be able to predict the response of Reed Elsevier, which disturbingly boasts regularly of the impact of The Lancet on global health-using it as a moral fig leaf. ${ }^{7}$ The company says that it is legal to sell arms, that the trade is tightly regulated, and that arms are clearly needed in a dangerous world. Unfortunately, the scale of sales is clearly excessive - and the harm that results is experienced mostly by women and children in the poorest countries, the very people for whom The Lancet speaks. The easy availability of guns also contributes to the gunning down of teenagers in South London.

The Lancet has acknowledged its discomfort. ${ }^{6}$ In 2005 it published a letter from 16 readers calling on Reed Elsevier to stop its involvement in the arms trade. ${ }^{8}$ That involvement, wrote the readers, was 'incompatible with The Lancet's guiding principles, Reed's subscription to the UN Global Compact, and the ethics of many of its contributors, readers, editors, and reviewers.' In the same issue the editors and international advisory board of The Lancet bravely and 'respectfully' asked 'Reed Elsevier to divest itself of all business interests that threaten human, and especially civilian, health and well-being. ${ }^{6}$

Unfortunately, Reed Elsevier didn't. So what now? The Joseph Rowntree Charitable Trust has spent three years trying to persuade the company to rethink its engagement with arms sales, but has failed - so it has sold its shares in the company. But what might be the actions of the editors, authors and readers of not only The Lancet but also the other 2000 medical and scientific journals published by Reed Elsevier? Alone they might achieve little, but together they might force the company to change, not by appealing to its non-existent conscience but through threatening its business.

It is the scientific and medical part of Reed Elsevier's business that is the most profitable: in 2005 its sales totalled $£ 1436$ million, or $28 \%$ of total Reed Elsevier sales, and its profits were $£ 449$ million, or $37 \%$ of the company's total profits. Indeed, Reed Elsevier plans to sell its education division, which is not nearly so profitable. The scientific and medical part of the business is so profitable because of the extraordinary value of the science it publishes. But the value in that research is created not by Reed Elsevier but by the scientists and academics who produce the research, peer review it, and edit most of the journals. This is where Reed Elsevier is vulnerable-were those researchers to go elsewhere, the company would promptly pull out of arms exhibitions. And, of course, those researchers might leave and never return.

It is essential, however, to act together. Somebody needs to orchestrate a campaign. The people in the strongest position to do so are the authors and readers of The Lancet and the 2000 other journals. Who will take the lead? 
Competing interests $\mathrm{RS}$ is a member of the board of the Public Library of Science and a critic of journals and journal publishers. Before writing this piece he was invited by the leaders of Elsevier to speak to them at a meeting in Bavaria.

\section{Richard Smith}

Former editor, BMJ

E-mail: richardswsmith@yahoo.co.uk

\section{REFERENCES}

1 Roberts L, Lafta R, Garfield R, Khudhairi J, Burnham G. Mortality before and after the 2003 invasion of Iraq: cluster sample survey. Lancet 2004;364:1857-64

2 Burnham G, Lafta R, Doocy S, Roberts L. Mortality after the 2003 invasion of Iraq: a cross-sectional cluster sample survey. Lancet 2006;368:1421-8

3 MacDonald R. Where next for arms control? Lancet 2006;368:713-4

4 Southall DP, O'Hare BAM. Empty arms: the effect of the arms trade on mothers and children. BMJ 2002;325:1457-61

5 Murray CJ, Lopez AD. Alternative projections of mortality and disability by cause 1990-2020: Global Burden of Disease Study. Lancet 1997;349:1498-504

6 The Lancet and The Lancet's International Advisory Board. Reed Elsevier and the arms trade. Lancet 2005;366:868

7 Cowden SJ. Reed Elsevier and the international arms trade-Reed Elsevier's reply. Lancet 2005;366:889-90

8 Feder G, Rohde JE, Sebastian MS, et al. Reed Elsevier and the international arms trade. Lancet 2005;366:889

\section{Diabetes epidemic in the South Asian Diaspora: action before desperation}

The tsunami wave of diabetes mellitus and its health and economic consequences is threatening much of the world. The need to prevent and control this debilitating chronic disease is urgent, before desperation sets in.

The International Diabetes Federation estimated that the number of people living with diabetes will rise from 194 million in 1993 to 333 million in $2025 .{ }^{1}$ In the USA, the prevalence of type 2 diabetes has doubled from $4 \%$ to $8 \%$ over the past four decades. In Asia, the epicentre of the coming pandemic of diabetes, profound socioeconomic and demographic changes, with increasing affluence and changing lifestyles causing obesity, are fuelling the problem. Consequently, the Indian subcontinent could be one of the leading contributors to global diabetes by 2025 .

The South Asian diaspora is prone to developing diabetes, a phenomenon known since the mid 20th century. South Asians develop diabetes earlier in life, at lower levels of obesity, suffer longer with complications and have a subsequent higher mortality risk than their White European counterparts. Childhood obesity and consequent type 2 diabetes is also no longer rare.

UK South Asian subgroups, in all their heterogeneity, have an increased prevalence of diabetes: population data using the oral glucose tolerance test in adult populations gives an estimate of about $20 \% .^{2}$ UK South Asians have a four- to six-fold increased prevalence of type 2 diabetes compared to the White European population. Unsurprisingly, cardiovascular disease ${ }^{3}$ is very common. Standardized mortality rates for South Asians are 50\% higher than the general population, with a great deal of premature mortality. Complications other than ischaemic heart disease include renal failure and stroke.

So why are South Asians at an increased risk of diabetes? No specific genetic hypothesis has yet explained the excess of diabetes in South Asians. In the 1960s, Neel postulated the 'thrifty genotype' hypothesis ${ }^{4}$ whereby people who possessed genes facilitating fat storage during food abundance would have a survival advantage during later famine. The current state of affairs - abundance with little famine - would make such an advantage a liability. There is little evidence, however, that over recorded history the Indian subcontinent has been particularly prone to famines compared to other parts of the world (with the possible exception of the short period when the British ruled India). The environment clearly plays an aetiological role. An urban/rural divide has been described in several countries and in particular in India. Urbanization, rather than migration per se, as a fuel to the development of diabetes is unquestionable. The UK South Asian population is certainly more sedentary than its counterpart White European population.

Impaired glucose tolerance is a precursor to diabetes and a propensity to diabetes may develop early in life. ${ }^{5}$ Low birth weight and intrauterine growth retardation in South Asians have been postulated to carry increased risks of diabetes later in life. ${ }^{5}$ South Asians born in the UK to mothers themselves born in the UK also have comparatively low birth weight. Yajnik showed that babies of Indian mothers had higher cord blood insulin concentrations than White European babies and these higher levels correlated with sub-scapular skinfold thicknesses. These 'thin-fat' Indian babies become more insulin resistant than their White European counterparts. ${ }^{6}$ The phenomenon of low birth weight with subsequent accelerated growth is widely seen in South Asian children and may contribute to the development of insulin resistance.

Increased visceral adiposity (measured as waist circumference) is more common in South Asians and denotes an individual at higher cardiovascular risk. The prevalence of obesity in India is low (2.2\%) but diabetes prevalence in 
some metropolitan areas is as high as $12 \% .^{7}$ South Asians suffer the consequences of being overweight at lower levels than their White European counterparts, leading the World Health Organization to propose lower cut-off points for obesity for Asian ethnic groups. Fat distribution possibly also differs in South Asians, with a new hypothesis suggesting they have an insufficiently developed lower limb fat compartment and more developed metabolically active compartments (upper body). This might explain South Asians' tendency to possess atherogenic dyslipidaemia and a predisposition to endothelial dysfunction.

How do we translate this understanding of basic science into clinical practice? There is a paucity of clinical trial data to help. Screening, early diagnosis and aggressive control of hyperglycaemia and other cardiovascular risk factors may reduce morbidity and mortality from diabetes. Lifestyle interventions to prevent hyperglycaemia and diabetes would be even better. Trials of lifestyle interventions for the prevention of diabetes are starting in UK South Asians. Several studies have shown that lifestyle changes and some medications may prevent type 2 diabetes. Whilst we await specific trial data for South Asians, it is likely that similar strategies targeting weight reduction would be more cost effective than treating the consequences of diabetes. Lifestyle improvements at all ages, together with effective management of other cardiovascular risk factors, are sensible and should be instituted without delay in high risk groups.

What, however, defines a high risk individual? Are Framingham cardiovascular risk tables accurate enough to apply to pre-diabetic South Asians? The South Asian Health Foundation advocates weighting of risk calculations. ${ }^{8}$ The National Institute for Clinical Excellence (NICE) in England and Wales recommends that all patients with diabetes with a 10 year CHD risk $>15 \%$ be offered a statin. This accommodates $\sim 70 \%$ of all patients with diabetes and the remaining 30\% simply fail to meet this threshold due to age alone. Denying cardiovascular prevention interventions to these individuals whilst atherosclerosis and subclincial disease develop is questionable, particularly in South Asians, who develop diabetes much earlier and have greatly accelerated atherosclerosis. Type 2 diabetes is widely accepted as a cardiovascular risk equivalent ${ }^{9}$ and the evidence base for treatment of people at high cardiovascular risk with statins (HMG CoA reductase inhibitors) is so compelling that all South Asians with diabetes should be considered for such therapies.

The cost of inaction is clear and should fuel the development of integrated public health approaches. Investment in such strategies will not only improve the lives of millions across the globe but also produce healthier economies. It is therefore timely that the South Asian Health Foundation has convened an international meeting to focus on diabetes in the South Asian Diaspora. ${ }^{10}$ Appropriate action now is better than desperation in the decades to come.

Competing interests $\mathrm{KCRP}$ and RSB: over the past 10 years we have attended educational meetings, received travel grants, honoraria for lectures or advisory boards from a number of pharmaceutical companies including AstraZeneca, Pfizer, Merck, MSD, Medtronic, Takeda, Novartis and Sanofi-Aventis. Through the South Asian Health Foundation and other roles we advocate for vigorous action and research to prevent diabetes and cardiovascular diseases in all populations, including South Asians.

\author{
Kiran C R Patel ${ }^{1}$ Raj Bhopal ${ }^{2}$ \\ ${ }^{1}$ Consultant Cardiologist and Honorary Senior Lecturer, \\ University of Birmingham, and Chairman of the Trustees of the \\ South Asian Health Foundation \\ E-mail: drkiranpatel@sahf.org.uk \\ ${ }^{2}$ Bruce and John Usher Professor of Public Health, University of Edinburgh, \\ and Patron to the South Asian Health Foundation \\ E-mail: Raj.Bhopal@ed.ac.uk
}

\section{REFERENCES}

1 King H, Aubert RE, Herman WH. Global burden of diabetes, 19952025: prevalence, numerical estimates, and projections. Diabetes Care 1998;21:1414-31

2 Bhopal RS, Unwin N, White M, et al. Heterogeneity of coronary heart disease risk factors in Indian, Pakistani, Bangladeshi and European origin populations: cross sectional study. BMJ 1999;319:215-20

3 Kooner J, Chambers JC. Conceptualising the causes of coronary heart disease in South Asians. In: Patel KCR, Bhopal RS (eds). The Epidemic of Coronary Heart Disease in South Asian Populations: Causes and Consequences. Birmingham: South Asian Health Foundation, 2001

4 Neel JV. Diabetes mellitus: a 'thrifty' genotype rendered detrimental by 'progress'? Am J Hum Genet 1962;14:353-62

5 Fall C. Fetal and early life origins of cardiovascular disease in South Asians. In: Patel KCR, Bhopal RS (eds). The Epidemic of Coronary Heart Disease in South Asian Populations: Causes and Consequences. Birmingham: South Asian Health Foundation, 2001

6 Yajnik CS, Fall CH, Coyaji KJ, et al. Neonatal anthropometry: the thin-fat Indian baby. The Pune Maternal Nutrition Study. Int J Obes Relat Metab Disord 2003;27:173-80

7 Ramachandran A, Snehalatha C, Kapur A, et al. High prevalence of diabetes and impaired glucose tolerance in India: National Urban Diabetes Survey. Diabetologia 2001;44:1094-101

8 South Asian Health Foundation consensus statement. Statins in South Asians. Available at http://www.sahf.org.uk/ SAHF_statement_Statins_in_Asians.pdf (accessed 06/02/2007)

9 Haffner SM, Lehto S, Ronnemaa $\mathrm{T}$, et al. Mortality from coronary heart disease in subjects with type 2 diabetes and in non-diabetic subjects with and without prior myocardial infarction. $N$ Engl $\mathrm{J} \mathrm{Med}$ 1998;339:229-34

10 South Asian Health Foundation consensus statement. Diabetes and the South Asian diaspora. Available at http://www.sahf.org.uk/ Appendix_D_Programme.pdf (accessed 06/02/2007) 